\title{
Industry 4.0: The role of human resource professionals
}

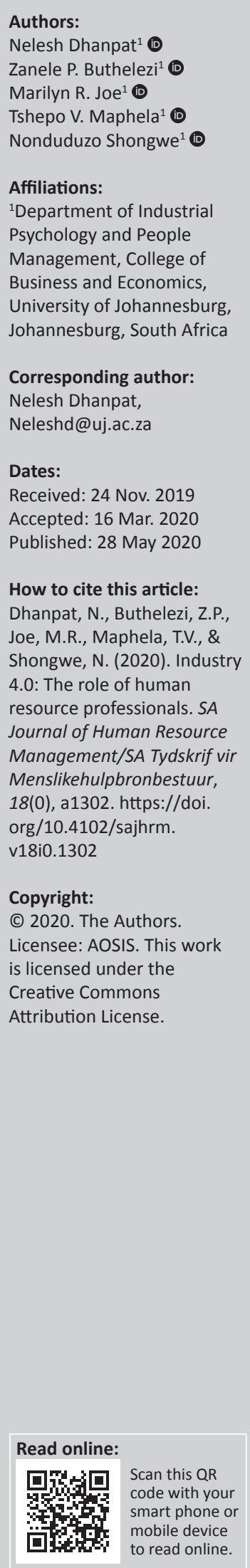

Orientation: Organisations are at the forefront of industry 4.0 and employees are witnessing the changes it brings.

Research purpose: The objective of this study was to explore the role of human resource (HR) professionals in navigating industry 4.0.

Motivation for the study: There is scant scientific research on the role of HR professionals in industry 4.0 within the South African context, although there are workshops and seminars in the field.

Research approach/design and method: A qualitative research approach is used within an interpretivist research paradigm. We interviewed a purposive sample of $12 \mathrm{HR}$ professionals. Semi-structured interviews were conducted to capture perceptions of HR professionals, and a thematic analysis was used to extract themes.

Main findings: Seven prominent themes emerged revealing that HR professionals need to assume roles as strategic business partners and talent managers, necessitating HR competencies such as creative innovator, change agent, strategic partner and people enablement to take advantage of the opportunities of industry 4.0 and mitigate the associated challenges.

Practical/managerial implications: HR professionals can use the findings as a basis for considering their role in industry 4.0. We propose a preliminary holistic model for navigating industry 4.0. Future researchers may use this study as a point of departure within the South African context.

Contribution/value-add: There is limited research on this topic matter and is a response to this. The study makes an important practical and scientific contribution to understanding the role of HR professionals as it affirms their function has become an essential part of industry 4.0 .

Keywords: industry 4.0; HR professionals; competencies; industrial revolution; human resource management.

\section{Introduction}

Industry 4.0 is a phenomenon that is already upon us and to gain competitive advantage, organisations need to change their attitudes towards the changing environment. Developed countries are already experiencing transformation caused by industry 4.0 in their manufacturing environments, and changes are anticipated to expand around the world in the next few years because industrial revolutions are always stimulated by the technological developments of a country. The areas affected by the transformation are not only relevant to manufacturing environment but will also have an impact on the essence of employees' duties, which are likely to change employee prospects of the human resource (HR) profession (Kazançoğlu \& Ozkan-Özen, 2018).

Advanced technology is at the centre of the current industrial revolution (Jesuthasan, 2017). Digital technology is changing the workplace as it alters the way in which HRs connect with each other and the organisation (Jesuthasan, 2017). A new revolution of innovative technology has arrived, in which artificial intelligence and machinery play a pivotal role in maximising productivity and enhancing wealth creation (Schäfer, 2018). Robotics are used in organisations to automate activities that are monotonous and easily understood, and artificial intelligence assists in complex decision-making through projecting algorithms (Parry \& Battista, 2019). The concepts of industry 4.0 and fourth industrial revolution are used interchangeably in this study.

\section{Purpose}

Digitisation has an impact on human capital as their skills become redundant (Rana \& Sharma, 2019). Industry 4.0 presents the challenge of unemployment, although it has the potential to open 
doors for the creation of new jobs (Naudé, 2019). It is therefore imperative that HR professionals remain relevant in the industry to keep their organisations up to date with the transition, as the implementation is unavoidable (Ślusarczyk, 2018). There is a need to determine how HR professionals might be solution-drivers in the HR discipline and during the advent of industry 4.0. Human resource professionals are concerned with overseeing the HR of organisations, which, through industry 4.0 , will be affected by technological tools and innovative technology (Jesuthasan, 2017). Technological disruption, robotics and automation threaten to replace low-skilled, routine jobs (Naudé, 2019). The increase in technological capability will not only cause an increase in unemployment but will also change the nature of work and the workforce because of the underlying trends in technology that accelerate job automation (Rana \& Sharma, 2019; Shava \& Hofisi, 2017).

Employee experiences and their work are encapsulated within human resources. There is a need to understand the influence of industry 4.0 not only on employees and their jobs, but also on the very nature of HR roles and associated functions. It is essential to evaluate the part that HR professionals will play during this revolution. The aim of this research is therefore to establish how factors associated with the fourth industrial revolution will influence the role of HR professionals.

\section{Literature review}

Industry 4.0 will necessitate certain new skills and competencies from employees (Łupicka \& Grzybowska, 2018). However, before these changes influence the human capital, they influence HR professionals, forcing them to evaluate the functions and roles they play in industry 4.0, and to be the first to navigate their direction in this technologically driven revolution.

\section{The role of human resource professionals}

There are various roles HR professionals perform, namely, employee advocate, human capital developer, functional expert, strategic partner and leader (Ulrich \& Brockbank, 2005). The role of HR professionals as employee advocates involves addressing the current needs of employees by listening and empathising with them (Bakuwa, 2013; Mamman, Rees, Bakuwa, Branine, \& Kamoche, 2019). The employee advocacy role requires HR professionals to serve the interests of employees, as well as execute other roles towards stakeholders of the business that recruited the employee (Mamman et al., 2019). This role can be used to mitigate the negative effects of anxiety and career doubt (Rizvi, 2011), which is vital in industry 4.0 as the introduction of new of technology results in job collapse, deskilling, job insecurity and increasing inequities (De Ruyter, Brown, \& Burgess, 2019). Human resource professionals as employee advocates need to engage with employees, establish personal career objectives for them and formulate a plan of action to achieve these objectives (De Ruyter et al., 2019; Sharma, 2012).
The human capital developer role entails the management and development of employees to meet future needs of the organisation (Mamman \& Kulaiby, 2014). The role of HR professionals as human capital developers involves overseeing and advancing HR collectively or individually, with the objective of equipping employees to thrive in the future (Bakuwa, 2013). Industry 4.0 brings about new technological advancements and job opportunities (De Ruyter et al., 2019), and employees will therefore have to update their competencies as demanded by this new industry (Özüdoğru, Ergün, Ammari, \& Görener, 2018). As such, employees will have to be retrained to accommodate this transformation.

The functional expert (previously known as administrative expert) role is associated with the human capital practices that are key to the HR value (Bakuwa, 2013). This role requires HR professionals to develop HR systems and arrange for HR development (HRD) audits to keep abreast of how HRD systems are functioning in the organisation (Sharma, 2012). Human resource professionals as functional experts contribute towards giving their organisation a competitive edge in terms of their human capital by selecting and hiring the best candidates (Sharma, 2012).

The strategic partner role of HR professionals comprises of dimensions such as consultant, business expert, knowledge manager, change agent and strategic HR planner who facilitate the HR systems to achieve the organisational goals (Bakuwa, 2013). The strategic partner role requires HR professionals to identify the main areas requiring attention with regard to people and technology (Sharma, 2012). Strategic HR activities help boost the productivity of employees, and future productivity results should indicate how employees use technological innovations (Al Mamun, Shamima, \& Islam, 2014). In the age of digitisation it is vital for HR professionals to become change agents; they need to assess the current state of the organisation, deal with employees' resistance to change and provide employees with the necessary competencies to deal with changes (Sharma, 2012; Sheehan, De Cieri, Greenwood, \& Van Buren, 2014). Human resource should start by preparing the changes they will need to meet the needs of organisational digital transformation (DiRomualdo, El-Khoury, \& Girimonte, 2018).

In a leadership role, $\mathrm{HR}$ professionals are required to act as credible leaders and partner with other leaders to set and improve the level of strategic thinking (Bakuwa, 2013; Mamman \& Kulaiby, 2014; Sheehan et al., 2014). The leader role relates to the credible activist competency of HR professionals, which requires them to be self-aware and dedicated to developing their profession (Sheehan et al., 2014; Ulrich, Younger, Brockbank, \& Ulrich, 2013).

\section{Key competencies needed by human resource professionals in industry $\mathbf{4 . 0}$}

In broadest terms, competencies required for industry 4.0 include technical, managerial and social. Technical competencies refer to knowledge, skill or abilities needed to perform a specific 
task (Feng \& Richards, 2018). Managerial competencies are defined as skills and abilities for general problem-solving and decision-making (Łupicka \& Grzybowska, 2018). Social competencies are defined as the maintenance of interpersonal relationships in the organisation, in turn necessitating communication skills (Łupicka \& Grzybowska, 2018).

The HR competency study conducted by Ulrich, Younger, Brockbank and Ulrich (2012) narrows this broad overview and identifies a few fundamental competency domains, the first of which is a strategic positioner. This refers to the ability to interpret external trends (in the fourth industrial revolution, mainly centred around advancement in technology), integrate them into internal actions and communicate clearly the impact these have on their workforce (Burmeister, Lüttgens, \& Piller, 2016). In addition, a capability builder should possess the skill to build critical organisational capabilities (Ulrich, Younger, Brockbank, \& Ulrich, 2011). With the amount of change taking place as a result of industry 4.0 (Jesuthasan, 2017), being a change champion is a crucial competence to have - the ability to usher organisational change and implement change processes at the same pace that change is happening externally. Lastly, technology proponents are vital because of the fact that we are in the digital age (Jesuthasan, 2017).

In addition to the above competencies, total reward stewards, analytics and compliance managers are also necessary. Total rewards steward refers to having a scheme in place that will be meaningful and exciting to existing employees, as well as attract potential employees (Prikshat, Biswas, Nankervis, \& Hoque, 2018). The analytics designer and interpreter competency describes an HR professional's skill in using analytics to improve decision-making. Lastly, compliance manager refers to the ability to use regulatory guidelines to manage processes related to compliance (Prikshat et al., 2018).

\section{Human resource operations and their effectiveness}

As the rate of automation increases, the required number of employees who perform redundant, process-based jobs will decrease, whether in production or the office environment (Baldassari \& Roux, 2017). Industry 4.0 is supported by technology and developments in production; however, HRs remain the cornerstone of it all (Liboni, Cezarino, Jabbour, Oliviera, \& Stefanelli, 2019), with the field of HRs involving the way in which people relate to one another, the way they relate to technologies and inventions developing in the industry and the way they relate to the new business model (Liboni et al., 2019). It is imperative for organisations to align their HR practices and plans with industry 4.0, including areas such as the development of skills and employment of workforce (Sivathanu \& Pillai, 2018). Traditionally, the role of an HR department in an organisation is to manage all facets that relate to an employee's cycle, from recruitment to exit phase (Sivathanu \& Pillai, 2018). Even though the role of HR is important to organisational development, in recent times, HR departments have been perceived to be an operational department with unproductive procedures that are aggravated by outdated technology (Sivathanu \& Pillai, 2018). It is this study's aim to investigate ways for HR departments to remain current with the advent of industry 4.0.

\section{Method \\ Research approach}

This study employed a qualitative research approach. This approach was considered suitable for the study as it provided useful insights into how HR professionals understand the influence of industry 4.0 .

\section{Research philosophy}

This study adopted an interpretivist paradigm. The stance of the study was ontological in nature as it studied industry 4.0 (current reality) by exploring the role of HR professionals, interrogating the impact of industry 4.0 on them and establishing the competencies needed by HR professionals to operate in industry 4.0 .

\section{Population and sample}

The sample comprised $12 \mathrm{HR}$ professionals. When findings are sufficient (Box, 2014), which, in the case of this study, was deemed as having been reached after 12 interviews. A non-probability purposive sampling method was used to recruit HR professionals, which enabled the objectives of the study to be achieved. The researchers contacted professional bodies to gain access to senior-level HR professionals. All participants had to be employed at middle management or above and work within HR or the academic field of HR management. The sample comprised six men and six women. The mean age was 43 years, and in terms of ethnic distribution the sample had participants as follows: black people $=5$, mixed race $=1$, Indian $=2$ and white people $=4$. The full biographical details of the participants are given in Table 1.

\section{Research instrument}

Semi-structured interviews were selected as the data collection strategy. The interviewer both used a prepared set of questions to urge the respondent to discuss the themes of interest, as well as formulated new questions during the interview (Collis \& Hussey, 2014). An interview guide was developed based on the literature, which included open-ended questions. Questions were formulated so as to encourage participation. Probing questions were formulated to obtain rich data and active listening was required (Leavy, 2017). The following are examples of questions that were posed in the interviews: Describe how can HR assist in preparing the organisation for industry 4.0. Describe the opportunities that industry 4.0 will bring about in terms of people management. Describe how can HR assist in preparing the organisation for industry 4.0.

\section{Data collection}

Participants were approached individually through personal emails, and after agreeing to participation, an appropriate time for the interview was scheduled. On average the 
TABLE 1: Participant profile.

\begin{tabular}{|c|c|c|c|c|c|c|c|}
\hline Participant & Age & Race & Gender & Tenure (years) & Role & Level & Industry \\
\hline 1 & 44 & Black people & Male & 16 & Manager: talent management & Senior manager & Automotive \\
\hline 2 & 38 & Black people & Male & 9 & Specialist: HR & Middle level & Automotive \\
\hline 3 & 36 & Indian people & Female & 1 & HR business partner & Senior level & Mining \\
\hline 4 & 50 & Mixed race & Male & 6 & HR manager & Middle level & Higher education \\
\hline 5 & 31 & Indian people & Female & 1 & Senior HR business partner & Senior level & IT sector \\
\hline 6 & 58 & Black people & Male & 8 & $\begin{array}{l}\text { Lecturer } \\
\text { Director }\end{array}$ & Senior level & Higher education \\
\hline 7 & 54 & White people & Female & 15 & Executive director & Senior level & Graduate recruitment industry \\
\hline 8 & 35 & Black people & Female & 5 & HR manager & Middle level & Mine \\
\hline 9 & 38 & Black people & Female & 1 & Lecturer & - & Higher education \\
\hline 10 & 36 & White people & Male & 9 & HR senior manager & Senior level & Retail and manufacturing \\
\hline 11 & 45 & White people & Male & 11 & Senior HR specialist & Senior level & Oil industry \\
\hline 12 & 52 & White people & Female & 10 & Human capital manager and business consultant & Senior level & IT sector \\
\hline
\end{tabular}

$\mathrm{HR}$, human resource.

interviews last between $45 \mathrm{~min}$ and $60 \mathrm{~min}$ and were conducted at the convenience of the participant either at their office or via Skype. Interviews were tape recorded, and thereafter they were transcribed.

\section{Data analysis and interpretation}

Thematic analysis was used; this is a form of data analysis that encompasses classifying and arranging themes across a data set (Braun \& Clarke, 2006). Identifying common themes enables the researcher to record the fundamental meaning of the subject matter. Trustworthiness of the data was ensured through Lincoln and Guaba's (1985) criteria: credibility, transferability, dependability and confirmability. Credibility was ensured by establishing whether the information provided by participants is reflected in the findings (Esterberg, 2002). Transferability was achieved by providing rich descriptions of the data (Bowen, 2005). Dependability of the research refers to the degree to which analysis processes or data collection instruments will obtain consistent results (Saunders, Lewis, \& Thornhill, 2015). The confirmability of the findings were ensured by presenting the words of the participants without interpretations made by the researcher The terms transferability, credibility, conformability and dependability are used to explain how trustworthy a study is (Elo et al., 2014). These aspects are widely recommended by qualitative researchers and hence were incorporated into the study to ensure the integrity and quality of data (Shenton, 2003).

\section{Findings}

The purpose of this study was to understand the role of HR professionals in navigating industry 4.0. Through thematic analysis seven themes were established and were perceived by HR professionals as significant for the role of $\mathrm{HR}$ professionals in industry 4.0. Table 2 provides insights into the seven themes that emerged from the interview. Table 2 provides the frequency with which each of the themes emerged. Table 2 reveals that 'HR's role in industry 4.0 ' occurred most frequently, and the sub-theme 'HR delivery' occurred the most. This was followed by 'HR 4.0 competencies' and 'Industry 4.0 in organisations'. The sub-themes that occurred most frequently were 'Change agent' and 'Embracing new technology', respectively. Least frequent occurrences were 'Industry 4.0 and HR Strategy' and 'Challenges of 4.0 '.

\section{Theme 1: Industry 4.0 in organisations}

The findings relating to industry 4.0 in organisations included four sub-themes, namely, embracing new technology, new ways of work, automation and HR agility.

\section{Embracing new technology}

Participants stated that their organisations had embraced technology and information systems (P8), citing examples such as 'the introduction of robotics in the production area to take over the duties that were more monotonous and also having $[a]$ chatbot that assists employees in any IT issues' (P1). Participant 5 noted that 'the more technology-driven applications [that] come out there, the more business or opportunity there is out there to test those softwares'.

\section{New ways of work}

Participants highlighted the need for new ways of work, such as 'virtual worktops, flexi-hours because we couldn't have our staff sitting for four hours in traffic' (P5). Participant 2 noted the importance of 'culture and infrastructure' working together with 'policies and procedures' to form the new way of work:

'I think it's important that fundamentally we need to review how we do things in our business, because the strategies that we used to use three-four years ago it's not relevant anymore.' (Participant 4)

\section{Automation}

With regard to automation, participants placed emphasis on the use of automation to perform manual tasks, even describing it as 'a new evolution' into 'a more global ... automated space' (P3). Other participants described specific automated systems in use at their companies, such as participant 10, who stated that one 'can actually see the manpower through the app, and you can just use your finger to sign the document instead of doing it manually or otherwise'. Participant 4 praised the system at his organisation, 
TABLE 2: Themes and sub-themes identified from interviews.

\begin{tabular}{|c|c|c|c|}
\hline Theme & Description & Sub-theme & Frequency \\
\hline \multirow{4}{*}{$\begin{array}{l}\text { Theme 1: } \\
\text { Industry } 4.0 \text { in organisations }\end{array}$} & \multirow[t]{4}{*}{ Industry 4.0 and its influence on organisations } & - Embracing new technology & 10 \\
\hline & & - New ways of work & 7 \\
\hline & & - Automation & 6 \\
\hline & & - HR agility & 6 \\
\hline \multirow{2}{*}{$\begin{array}{l}\text { Theme 2: } \\
\text { Industry } 4.0 \text { and HR } \\
\text { Strategy }\end{array}$} & \multirow[t]{2}{*}{ Digital transformation and its effects on the HR strategy } & - Digitisation of work & 9 \\
\hline & & - Delivery of work & 4 \\
\hline \multirow{3}{*}{$\begin{array}{l}\text { Theme 3: } \\
\text { Developing } 4.0 \text { competencies }\end{array}$} & \multirow{3}{*}{$\begin{array}{l}\text { The avenues through which HR professionals can develop } \\
\text { the competencies required to navigate industry } 4.0\end{array}$} & - Understanding the environment & 8 \\
\hline & & - Development programmes & 7 \\
\hline & & - Networking & 5 \\
\hline \multirow{4}{*}{$\begin{array}{l}\text { Theme } 4 \text { : } \\
\text { HR } 4.0 \text { competencies }\end{array}$} & \multirow{4}{*}{$\begin{array}{l}\text { The competencies required by HR professionals needed to } \\
\text { navigate through industry } 4.0\end{array}$} & - Change agent & 11 \\
\hline & & - Strategic partner & 10 \\
\hline & & - Creative innovator & 10 \\
\hline & & - People enablement & 9 \\
\hline \multirow{3}{*}{$\begin{array}{l}\text { Theme } 5 \text { : } \\
\text { HR's role in industry } 4.0\end{array}$} & \multirow{3}{*}{$\begin{array}{l}\text { The type of work the HR professionals will embark on } \\
\text { through initiatives of industry } 4.0\end{array}$} & - Strategic shift & 16 \\
\hline & & - Reskilling needed & 10 \\
\hline & & - Talent management & 7 \\
\hline \multirow{2}{*}{$\begin{array}{l}\text { Theme 6: } \\
\text { Challenges of } 4.0\end{array}$} & \multirow{2}{*}{$\begin{array}{l}\text { The complexities that HR professionals foresee with regard } \\
\text { to industry } 4.0\end{array}$} & - Uncertainty & 11 \\
\hline & & - Adapting to change & 7 \\
\hline \multirow{3}{*}{$\begin{array}{l}\text { Theme } 7 \text { : } \\
4.0 \text { opportunities }\end{array}$} & \multirow[t]{3}{*}{ Opportunities ushered in by industry 4.0} & - Innovation and improved systems & 9 \\
\hline & & - Enhanced talent management & 6 \\
\hline & & - Delivery of HR work & 5 \\
\hline
\end{tabular}

HR, human resource.

which dealt with 'appointments ... leave applications, ... documentation for recruitment, for selection in terms of ... most HR applications'.

\section{Human resource agility}

One participant stated that an 'agile environment ... forms part and parcel of industry $4.0^{\prime}$ (P2), although one participant noted that:

'[T] he focus on emerging technology has caused HR to amend its strategy to ensure that HR is ideally placed to be directly involved in the defining and fostering an organisational culture.' (Participant 1)

' $[W]$ e are slowly transitioning to people, but at a very slow pace and, purely because also there is, you have your organised labour which are your unions which also play a very vital role in the success of you transitioning and changing to the agility of the new HR.' (Participant 8)

\section{Theme 2: Industry 4.0 and human resource strategy}

Industry 4.0 and HR strategy relates to the digitisation of work, delivery of HR work and reskilling of employees.

\section{Digitisation of work}

The HR professionals noted that work has become digitised, citing examples such as the 'automating [of] rule-based work' (P3), robotics and even a chatbot (P8).

\section{Delivery of human resource work}

Participants also stated that industry 4.0 brings about changes in the delivery of HR work. Participants alluded that 'we are making strides in terms of improving the processes like ... workflow management systems' (P2). Participant 5 noted a need to 'basically change or transform HR or people engagement' as he was 'constantly dealing with people via technology if they are constantly working with ... other virtual teams', bringing into question the 'human interactive' (P5) element of HR. The difference in HR delivery because of automation may bring about a shift from people-orientated frustrations to system frustrations (P3).

\section{Reskilling}

In addition, participants highlighted the importance of reskilling employees and stated that 'the impact for us on the human capital management (HCM) side is huge. The technology is there but the skills are still following' (P12). The further importance of looking to the future came to the fore, with participant 2 noting that one must 'forecast and look at the talent, pipeline and the pool' and 'look at the future skills, the current skills that we have and how we're going to get those people into the level that we want' (P2).

\section{Theme 3: Developing 4.0 competencies}

The development of 4.0 competencies encompasses three sub-themes, namely, understanding the environment, development programmes and networking.

\section{Understanding the environment}

In terms of understanding the industry environment, participants stressed the need for being aware of current trends and adapting as such. Participant 2 warned against trying 'to be safe' or fostering a 'culture of being reactive', instead advocating to 'increase our mind' and 'try new things' (P2). Participant 11 noted that current thinking may become irrelevant very quickly because of the rate of change 
and therefore advised that one should 'be more proactive than reactive. We need to identify gaps in the market and explore them likewise' (P11). 'Being culturally and socially aware in order to lead' (P7) was given as markers of understanding the environment.

\section{Development programmes}

Participants placed emphasis on the need for 'organisational development plans [that are] intentional and upfront' (P8) that will assist HR in developing the competencies required in industry 4.0. 'Short courses, informal courses [and] attending workshops' (P1) were some suggestions for learning new skills, although, as participant 12 noted, 'some of these can be more attributes than skills' that may 'have to be developed by being involved in projects that are advanced and require artificial intelligence' (P12).

\section{Networking}

Participants highlighted the importance of 'networking, teamwork and coordinating with others' (P12) in industry 4.0. They suggested that they may seek out a 'collaboration space where [they are] able to network' (P2).

\section{Theme 4: Human resource 4.0 competencies}

The combination of sub-themes that relate to HR competencies includes being a strategic partner, change agent and creative innovator and the aspect of people enablement.

\section{Strategic partner}

Participants stated that core competencies would include 'strategic leadership' (P6) and being 'well-read so that they understand the trends' (P7) whilst 'looking long term' (P6). A strategic leader would engage in 'business partnering' (P2) and be able to consider 'the whole organisation systemically in terms of how the different facets or parts of the organisation will interact' (P6).

\section{Change agent}

Participants highlighted the ways in which HR will need to be able to respond to the changes that industry 4.0 will usher in. They should 'embrace change' (P6) to be facilitators or 'agents of change' (P2), as well as 'advise people on how to change things quickly' (P4). They will need to be 'resilient ... [in] managing change right' (P9) and show 'agility ... to quickly respond to changes' (P11).

\section{Creative innovator}

Anumber of the participants highlighted the need for 'creativity' (P11; P12) or 'creative thinking' (P10), 'problem-solving' (P11; P12) and 'critical thinking' (P10; P12) skills. Participant 12 also identified the need for 'emotional intelligence'.

\section{People enablement}

As an HR professional, one of the core competencies is knowing how to interact with people; in other words, the skill of 'relationship management ... [to] move people through change' (P7). 'Emotional intelligence' (P5) was once again highlighted because of the fact that 'people are different' (P5). Participant 10 stated that 'face-to-face interactions are essential to maintain relationships with clients', as are 'teamwork and ... coordinating with others' (P12).

\section{Theme 5: Human resource's role in industry 4.0}

Four sub-themes regarding HR's role in industry 4.0 emerged, namely, HR delivery, reskilling needed, strategic shift and talent management.

\section{Human resource delivery}

Participants highlighted the changes in terms of HR delivery, especially with regard to online work and available data. 'Most of my day-to-day work [is] online', stated one participant, who went on to add, 'I certainly feel my job has been made easier. In terms of recruiting ... put [a job advert] online and people apply there' (P10). Another explained, 'We've got a lot of data and analytics coming through so we can really see and read into the data' (P3). One participant predicted that 'the next big thing in HR is going to be about behavioural science' (P7) and that these data would enable us to forecast 'future trends' (P7).

\section{Reskilling needed}

The participants mentioned the important need for HR professionals to improve their 'skillset to match the advance $[d]$ technology' (P10) in preparation for 'what the world of the future is likely to be' (P4). Another participant explained how she had been sent on a 4-month 'fast-track upskilling programme' (P12). As a result, her 'skills are currently in demand' (P12) because 'all the other HR roles ... will eventually be affected' (P4).

\section{Strategic shift}

Participants highlighted the need for a strategic shift to ensure efficiency in industry 4.0. There is a greater focus on ensuring 'that the systems are in line with the cultures and practices in that specific organisation' (P9) and that influencing employees 'is very much about them understanding the new ways of work' (P7). Human resource professionals' roles have 'become more consultative; it doesn't stop with employees' (P5). One needs 'to be more proactive and engage with management and be more strategic on how we involve or implement change' (P5).

\section{Talent management}

With regard to talent management, participants emphasised the need to 'be way more proactive' (P12) in managing talent. Instead of reacting to retrenchments, lack of skills or something to go wrong, this participant suggested proactive 'workforce planning [to] find out what skills are needed, and ... start upskilling people now' (P12). Other participants recommended that organisations should be asking questions such as 'Are we delivering the right services, and do we have the right people to deliver the right services?' (P3) and, with the help of HR, taking action accordingly to make sure that 
the 'right people [are] in the right places' (P3), 'that people are engaged and that they understand what this industry entails' (P10).

\section{Theme 6: Challenges of 4.0}

Participants alluded that industry 4.0 will bring about uncertainty and adapting to change as major challenges.

\section{Uncertainty}

Participants indicated that majority of people have uncertainty about the future world of work. In an 'environment where already we are faced with people who are skilled but are unemployed' (P10), HR professionals will be required to manage the 'people element' (P6) of the system 'because [employees] were never prepared for what's coming' (P2). One participant described this as 'fear' (P7), which may be a 'problem that requires conflict management' (P10) should job losses occur.

\section{Adapting to change}

Seven participants touched on the subject of change. Some foresee 'resistance' (P7; P11) as 'people are scared of change' (as an extreme example mentioned by participant 1 , afraid of being replaced by machines) but 'scared of failing, too' (P11). However, HR professionals can assist employees to '[adapt] to changes in the environment' (P6) by 'adopting new principles' (P4) and 'training people who will be able to be relevant in the industry' (P6), beyond even the fourth industrial revolution and into the fifth (P6).

\section{Theme 7: 4.0 opportunities}

The sub-themes that fall under 4.0 opportunities are innovation and improved systems, enhanced talent management and delivery of HR work.

\section{Innovation and improved systems}

Industry 4.0 brings about improved HR management systems and innovative ways of work as identified by the participants, such as 'digital tools for planning, ... processing, communication, payments and ... digital tools to train' (P6). Participant 12 stated that 'innovation will be an opportunity for organisations to grow and develop', although participant 9 noted that they already had 'improved workforce management systems right'.

\section{Enhanced talent management}

According to participants, talent management will change in terms of 'education and training systems' (P12) and 'better utilising people skills and talent' (P8). 'People will be more empowered in their roles because they can do their work remotely' (P1), and HR professionals will be forced 'to be more aware of what is the next person's talents are' (P8).

\section{Delivery of work}

Participants further indicated 'changes in the organisation of work, with more remote and on-demand work becoming a standard' (P12). There will be a 'drive on how we better technology to engage with our employees' (P8), with 'virtual spaces [and] technological tools like Zoom' (P5) becoming more common and 'face-to-face contact with people' (P8) becoming less so. Things will be 'run by systems' (P8), meaning that 'the way people will do their jobs going forward might change dramatically' (P4).

\section{Discussion}

\section{Theme 1: Industry 4.0 in organisations}

Industry 4.0 is brought upon by technological developments and improvements that transform the way in which HR connects with each other and the organisation, and its impact on employees (Jesuthasan, 2017). The findings suggested four sub-themes related to industry 4.0 in organisations, namely, embracing new technology, automation, new ways of work and $H R$ agility. Industry 4.0 brings about new technological developments such as robotics, artificial intelligence and automation that have the potential to change the world of work, the skills of employees and introduce new job opportunities (De Ruyter et al., 2019). The findings of this research confirm the use of automation and artificial intelligence to optimise operations of day-to-day tasks but which otherwise may hinder the effectiveness of the HR division (Gikopoulos, 2019).

The research findings indicated the introduction of new working arrangements, including those of HR, as a result of industry 4.0, much of this through automation (Rana \& Sharma, 2019). The findings suggested that HR should move towards a strategic and agile standpoint (Rana \& Sharma, 2019).

\section{Theme 2: Industry 4.0 and human resource strategy}

Industry 4.0 influences HR operations (Liboni et al., 2019). Strategic HR functions help enhance the productivity of employees, and future results should indicate how employees use technological innovations (Al Mamun et al., 2014). The findings suggested three sub-themes associated with industry 4.0 and HR strategy, namely, the digitisation of work, delivery of HR work and reskilling of employees. Digitisation of work may enhance the effectiveness of operations; automation improves the effectiveness of HR departments by minimising costs, enabling operation at a faster pace and providing accurate data (Liboni et al., 2019). The findings indicated a transformation in the delivery of HR operations, such as the automation of HR processes because of emerging technologies, resulting in efficient and leaner HR teams (Liboni et al., 2019). Findings furthermore suggested the need to reskill employees; HR will require training to use emerging applications (Rana \& Sharma, 2019).

\section{Theme 3: Developing 4.0 competencies}

The transformational influence of industry 4.0 means that organisations and employees will need to place greater emphasis on developing competencies required in industry 
4.0 (Özüdoğru et al., 2018). The findings yielded three subthemes, namely, understanding the environment, development programmes and networking. The development of employee competencies is one of the crucial factors needed to succeed in early stages of the transition towards digitisation (Agostini \& Filippini, 2019). Findings suggest the need for being aware of trends in the industry and being able to adapt. Human resource should remain informed about technological shifts and remain adaptable to the changing labour market conditions to attract and retain staff and to develop new organisational models (Liboni et al., 2019). Moreover, participants emphasised the need for development programmes to fill the gap between current and required competencies. Industry 4.0 brings about disruptive changes and requires a fast adaption (Eberhard et al., 2017). Core skills that are currently desired in jobs will include skills not yet considered crucial to the job today. Therefore, organisations are required to provide their employees with development and training programmes (Eberhard et al., 2017). Participants indicated the importance of maintaining relationships with all stakeholders of a business and keeping abreast of technological innovations. This can be achieved by being informed of the changes through seeking information and resources (Ślusarczyk, 2018).

\section{Theme 4: Human resource 4.0 competencies}

Industry 4.0 is a revolution characterised by innovative technology where digitisation and artificial intelligence are the focal points in enhancing productivity (Schäfer, 2018). Therefore, it is imperative for HR competencies to follow suit and align with these foci. The findings proposed four sub-themes: change agent, strategic partner, creative innovator and people enablement. The results indicate that participants agree with the HR competency study by Ulrich et al., (2012), naming change champion and strategic positioner as necessary HR competencies. As change agents, HR professionals need to be able to steer and adjust to change as well as guide implemented change strategies (Ulrich et al., 2011). For appropriate strategies to be created, HR professionals need to be visible strategic partners who will interpret trends and integrate them within the organisation (Ulrich et al., 2011). Human resource builds value by enhancing the productivity and agility of human capital (Ulrich et al., 2012); hence, it is necessary to have competencies that will resonate with the human capital of the organisation. It is for this reason that HR needs to play a more visible leadership role in the transformation towards digitisation within organisations (El-Khoury, 2017). Human resource professionals need to oversee the advancement of human talent within the organisation and ensure that they are equipped with skills to thrive in the future (Bakuwa, 2013).

Also, the fact that the fourth industrial revolution is centred on advancement in technology (Burmeister et al., 2016) means that HR professionals and the organisation at large need to be innovative to keep up with the technological advancements. This results in the need to be a creative innovator. This sentiment was noted by the participants, who mentioned that creativity and critical thinking will help organisations flourish in the fourth industrial revolution.

Lastly, a crucial competency needed is that of people enablement. For the HR professional to be an efficient leader and manage talent accordingly, good interaction or relational skills are needed. Human resource professionals must possess the ability to foster relationships based on trust and reliability (Ulrich et al., 2011). Sound relationships, especially in times of change, have the potential to diminish resistance displayed by employees because of the trust and reliability created between employees and the HR professional.

\section{Theme 5: Human resource's role in industry 4.0}

There is a paradigm shift in the role of HR in transitioning into a strategic role that allows it to focus on broader aspects other than the administration role (Dhanpat, 2015). With industry 4.0, the role of HR will change and thus require HR professionals to be strategic partners of the organisation (Ulrich et al., 2013). The findings indicated that HR needs to ensure delivery, provide a strategic shift, contribute to reskilling needed and ensure effective talent management.

Participants suggested that there will be a change in terms of how HR delivers their work. Currently, organisations deal with numerous people issues, such as improved mobility, an inter-generational workforce, changing digital job descriptions and work-life balance (Rana \& Sharma, 2019). Therefore, it is imperative that HR improves its function to be digitally savvy and agile to be able to manage the distinctive, hyper-connected workforce (Rana \& Sharma, 2019). Moreover, emerging technologies and a different generation of employees will change HR processes such as talent on-boarding and offboarding, as well as learning and development (Rana \& Sharma, 2019). Thus, there is a need to reskill and upskill people to meet the changing demand of work, to ensure that employees have correct and pertinent skills to compete in industry 4.0 (Pedron, 2018).

Participants also suggested that there is a growing need for HR to manage talent. Technology has completely renewed the manner in which employees engage with their organisations (Rana \& Sharma, 2019). Therefore, it is important for HR to become responsive by shifting from a conventional, transactional scope of work (Rana \& Sharma, 2019), that is ensuring that the organisation has the right people at the right time for the right jobs. This can be accomplished by HR being proactive and providing training and development that meets the requirements of industry 4.0. This will allow employers to capitalise on increasing performance and productivity of the workforce (Ejovwokeoghene, Yewande, Oluseye, \& Joseph, 2018).

\section{Theme 6: Challenges of 4.0}

As much as industry 4.0 will bring about great opportunities that can be leveraged, it also brings forth certain challenges. 
These challenges refer to things that might hinder the organisations from successfully implementing the changes or exploring new business opportunities brought about by industry 4.0 (Prisecaru, 2016). The findings indicated two sub-themes, namely, uncertainty and adapting to change.

Participants suggest major challenges with industry 4.0 will be because of uncertainty because people do not know what to expect (Prisecaru, 2016). Several participants noted that the issue of possible job loss, as well as resistance to change, as people might not be comfortable to adapt their ways of working. Resistance is a challenge faced by any organisation undergoing change (Gupta, 2018); however, employers need to understand that there will be challenges like this and they need to act accordingly - adapting quickly and learning faster (Gupta, 2018). Strategic planning will become necessary to envisage possible challenges that could be faced in the future. Organisations will need to be future-facing to develop action plans and adapt to change quickly.

\section{Theme 7: 4.0 opportunities}

Industry 4.0 is changing the way in which organisations work (Jesuthasan, 2017). In trying to adapt to industry 4.0, organisations are forced to be innovative and think creatively. Innovative thinking increases the likelihood of new jobs being conceived, thereby creating more opportunities in organisations (Naudé, 2019). The findings suggested three sub-themes related to opportunities that arise as a result of industry 4.0, namely, innovation and improved systems, enhanced talent management and delivery of HR work. Technology brings together different technical and scientific disciplines, creating new and innovative growth opportunities ( $\mathrm{Xu}$, David, \& Kim, 2018), as well as improved and enhanced systems. As part of their leadership role, HR professionals should develop sound and promising talent strategies by examining the present strategy, improving upon this and implementing talent strategies aligned with the organisation's goals that promote the investment of workforce training (Deloitte Global, 2018). Delivery of work is changing because of improved technology, for example, making use of interactive voice-response systems to direct calls or using the Internet to interact with customers (Xu et al., 2018). In addition, improved technology also allows for delivery of work to be more efficient.

\section{Practical implications}

There is scant scientific research on the role of HR professionals in industry 4.0 within the South African context, although there are workshops and seminars being presented within the field. The findings of the study will have implications for the advancement of knowledge of HR professionals and their role in industry 4.0. The study provides insights to HR professionals on navigating industry 4.0. Qualitative insights were gained from HR professionals and HR academics. This category allowed to gauge insights provided by HR professionals in terms of industry and practice, although an academic perspective was considered necessary and can be used to assist HR professionals to acclimatise to industry 4.0 and to be prepared for the changes it brings.

Figure 1 shows a holistic model for HR professionals to navigate industry 4.0. The model encapsulates the environment

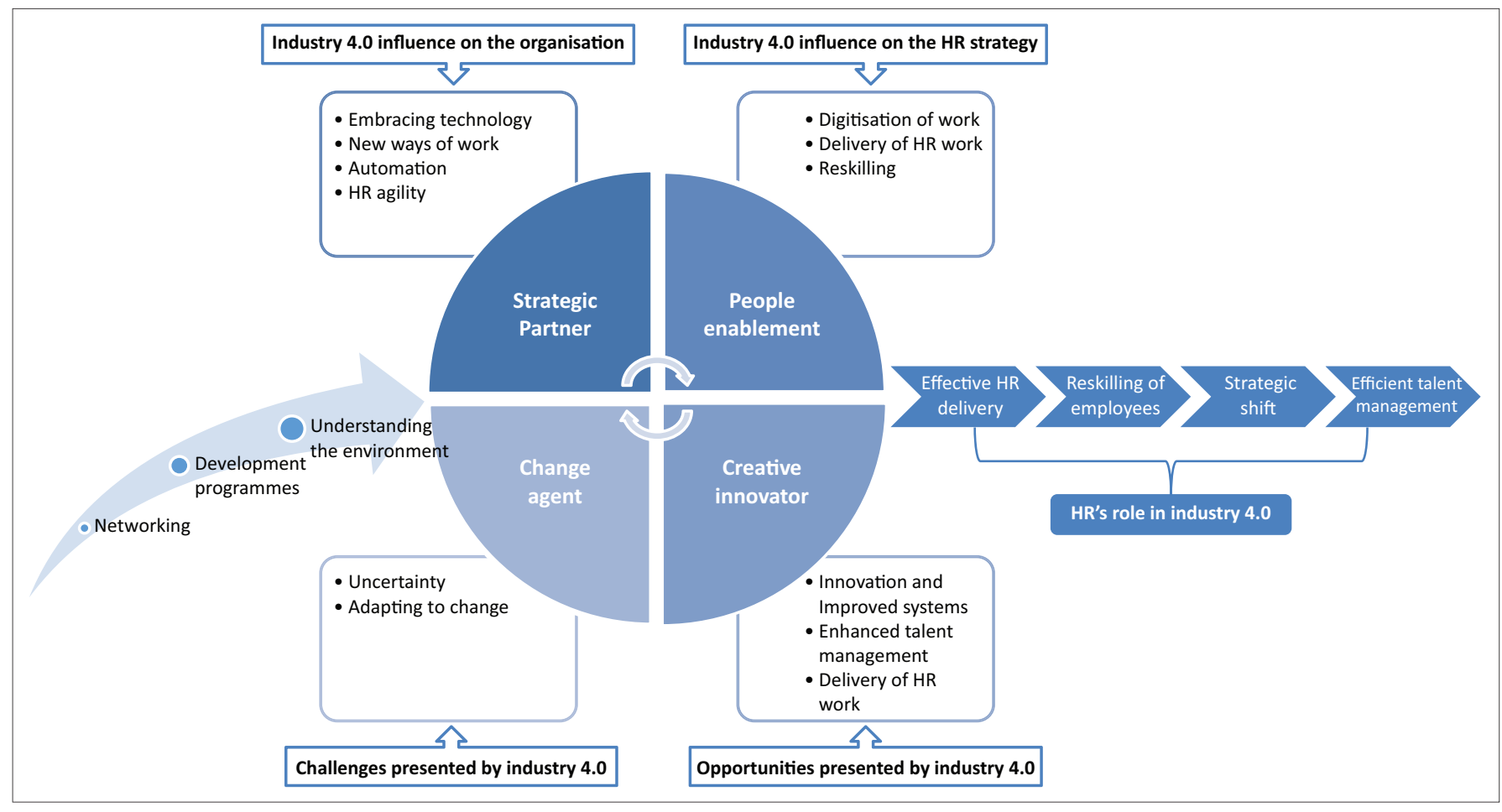

$\mathrm{HR}$, human resource.

FIGURE 1: A holistic model for navigating industry 4.0 for human resource professionals. 
of industry 4.0. It provides insights from the themes developed from this study to ensure that HR professionals are able, through a set of initiatives (networking, development programmes and understanding the environment), to develop competencies (strategic partner, people enablement, change agent and creative innovator), to navigate through industry 4.0 and hence ensure the effective delivery of HR work.

\section{Limitations and recommendations}

Although this study provides rich insights into the role of HR professionals in navigating industry 4.0, the information obtained was based on participants' subjective views. This was overcome through probing. The study was limited to HR professionals and academics, and thus the findings cannot be generalised to other professions. The participants in this study were lecturers, senior- and middle-level HR professionals. For future research, it is recommended that more senior-level HR professionals should be included in the sample, as well as industry 4.0 experts, to understand the role of HR in industry 4.0. It is recommended that this study be used as a point of departure for future research. In addition, HR professionals from organisations that are involved in industry 4.0 activities should be included in future research. Future studies may seek to use quantitative research methods to validate the conclusions and findings of the study.

\section{Conclusion}

This study set out to understand the role of HR professionals in industry 4.0. It provides new insights into the role of HR professionals in navigating industry 4.0. The study makes an important, practical and scientific contribution to the understanding of the role of HR professionals, as it affirms that the HR function has become an essential part of industry 4.0. Findings indicate that HR professionals play a vital role and establish their competencies to generate opportunities and mitigate challenges that industry 4.0 brings to the field of HR. Industry 4.0 presents uncertainties such as job loss, making it necessary for HR professionals to put human capital at ease and equip them with the skills needed to navigate industry 4.0 .

\section{Acknowledgements}

Thank you to Kevin Walker for his language editing services.

\section{Competing interests}

The authors have declared that no competing interest exists.

\section{Authors' contributions}

N.D. was the study leader and was responsible for consolidating and preparing the manuscript and conducted the data analysis. Z.P.B, M.R.J, T.V.M., and N.S contributed to the report for their research project and were responsible for the collection and transcribing of data.

\section{Ethical consideration}

In compliance with the University of Johannesburg's ethical clearance process, the participants' right to confidentiality and anonymity was ensured. Participation was on a voluntary basis and participants were granted the option to opt out of the study at any given time (Saunders, Lewis, \& Thornhill, 2015). Participants were assured protection against anything harmful; they had the right of freedom of choice as well as the right to information (through a signed informed consent form) regarding the processes and results of the study. All information provided by participants in this study was kept anonymous and confidential.

\section{Funding information}

This research received no specific grant from any funding agency in the public, commercial or not-for-profit sectors.

\section{Data availability statement}

Data sharing is not applicable to this article as no new data were created or analysed in this study.

\section{Disclaimer}

The views and opinions expressed in this article are those of the authors and do not necessarily reflect the official policy or position of any affiliated agency of the authors.

\section{References}

Agostini, L., \& Filippini, R. (2019). Organizational and managerial challenges in the path toward industry 4.0. European Journal of Innovation Management, 22(3), 406-421. https://doi.org/10.1108/EJIM-02-2018-0030

Al Mamun, M., Shamima, N., \& Islam, M. (2014). Human resources as strategic partner: Source of sustainable competitive advantage. ASA University Review, $8(2), 71-79$.

Bakuwa, R.C. (2013). Exploring the HR professionals' employee advocate role in a developing country: The case of Malawi. Australian Journal of Business and Management Research, 2(12), 39-48.

Baldassari, P., \& Roux, J.D. (2017). Industry 4.0: Preparing for the future of work. People \& Strategy, 40(3), 20-24.

Bowen, G. (2005). Preparing a qualitative research-based dissertation: Lessons learnt. The Qualitative Report, 10(2), 208-222.

Box, I. (2014). How many interviews are needed to in a qualitative research? Is there any rule or popular practice? [ResearchGate]. Retrieved from https://www. researchgate.net/post/How_many_interviews_are_needed_in_a_qualitative_ research_Is_there_any_rule_or_popular_practice

Braun, V., \& Clarke, V. (2006). Using thematic analysis in psychology. Qualitative ResearchinPsychology, 3(2),77-101.https://doi.org/10.1191/1478088706qp063oa

Burmeister, C., Lüttgens, D., \& Piller, F.T. (2016). Business model innovation for industrie 4.0: Why the 'industrial Internet' mandate a new innovation. Die Unternehmung, 70(2), 124-152. https://doi.org/10.5771/0042-059X-2016-2-124

Collis, J., \& Hussey, R. (2014). Business research: A practical guide for undergraduate and postgraduate students. New York, NY: Palgrave Macmillan higher education.

Deloitte Global \& the Global Business Coalition. (2018). Preparing tomorrows' workforce for the fourth industrial revolution for business: A framework for action. Retrieved from https://www2.deloitte.com/content/dam/Deloitte/global/Documents/AboutDeloitte/gx-preparing-tomorrow-workforce-for-4IR.pdf.

De Ruyter, A., Brown, M., \& Burgess, J. (2019). Gig work and the fourth industrial revolution. Journal of International Affairs, 72(1), 37-50.

Dhanpat, N. (2015). Turning the tide' a new wave of HR: Devolving HR capabilities to line managers. In Pan Pacific Business Conference (pp. 28-30). Hanoi: Pan Pacific Business Association.

DiRomualdo, A., El-Khoury, D., \& Girimonte, F. (2018). HR in the digital age: How digital technology will change HR's organization structure, processes and roles. Strategic HR Review, 17(5), 234-242.

Eberhard, B., Podio, M., Alonso, A.P., Radovica, E., Avotina, L., Peiseniece, L., ...SoléPla, J. (2017). Smart work: The transformation of the labour market due to the fourth industrial revolution (14.0). International Journal of Business and Economic Sciences Applied Research, 10(3), 47-66. 
Ejovwokeoghene, O.M., Yewande, O.A., Oluseye, O.O., \& Joseph, K.O. (2018). Talent management as a determinant of firm performance: A conceptual approach. Business and Social Sciences Journal, 3(1), 21-32.

Elo, S., Kääriäinen, M., Kanste, O., Pölkki, T., Utriainen, K., \& Kyngäs, H. (2014) Qualitative content analysis: A focus on trustworthiness. Sage Open, 4(1), 1-10.

El-Khoury, D. (2017). Digital transformation and the world-class HR difference. Strategic HR Review, 16(2), 86-88. https://doi.org/10.1108/SHR-01-2017-0001

Esterberg, K.G. (2002). Qualitative methods in social research. New York, NY: McGraw-Hill.

Feng, Y., \& Richards, L. (2018). A review of digital curation professional competencies: Theory and current practices. Records Management Journal, 28(1), 62-78. https://doi.org/10.1108/RMJ-09-2016-0022

Gikopoulos, J. (2019). Alongside, not against: Balancing man with machine in the HR function. Strategic HR Review, 18(2), 56-61. https://doi.org/10.1108/SHR-122018-0103

Gupta, S. (2018). Organizational barriers to digital transformation (Master of Science thesis). Stockholm: KTH Royal Institute of Technology.

Jesuthasan, R. (2017). HR's new role: Rethinking and enabling digital engagement Strategic HR Review, 16(2), 60-65. https://doi.org/10.1108/SHR-01-2017-0009

Kazançoğlu, Y., \& Ozkan-Özen, Y.D. (2018). Analyzing workforce 4.0 in the fourth industrial revolution and proposing a road map from operations management perspective with fuzzy DEMATEL. Journal of Enterprise Information Management 31(6), 891-907. https://doi.org/10.1108/JEIM-01-2017-0015

Leavy, P. (2017). Research design: Quantitative, qualitative, mixed methods, arts based, and community-based participatory research approaches. New York, NY Guilford Publications.

Liboni, L.B., Cezarino, L.O., Jabbour, C.J.C., Oliveira, B.G., \& Stefanelli, N.O. (2019) Smart industry and the pathways to HRM 4.0: Implications for SCM. Supply Chain Management: An International Journal, 24(1), 124-146. https://doi.org/10.1108/ SCM-03-2018-0150

Lincoln, Y.S., \& Guba, E.G. (1985). Naturalistic inquiry. Newbury Park, CA: Sage.

Łupicka, A., \& Grzybowska, K. (2018). Key managerial competencies for industry 4.0-practitioners', researchers' and students' opinions. Logistics and Transport, 3(39), 39-46. https://doi.org/10.26480/icemi.01.2017.250.253

Mamman, A., \& Kulaiby, K.Z. (2014). Is Ulrich's model useful in understanding HR practitioners' roles in non-western developing countries? An exploratory investigation across private and public sector organizations in the Sultanate Kingdom of Oman. The International Journal of Human Resource Management 25(20), 2811-2836. https://doi.org/10.1080/09585192.2014.914053

Mamman, A., Rees, C.J., Bakuwa, R., Branine, M., \& Kamoche, K. (2019). Employee advocacy in Africa: The role of HR practitioners in Malawi. Employee Relations, 41(1), 2-15. https://doi.org/10.1108/ER-12-2017-0296

Myers, M.D. (2013). Qualitative research in business and management. London: Sage.

Naudé, W. (2019). Brilliant technologies and brave entrepreneurs. Journal of International Affairs, 72(1), 143-158.

Özüdoğru, A.G., Ergün, E., Ammari, D., \& Görener, A. (2018). How industry 4.0 changes business: A commercial perspective. International Journal of Commerce and Finance, 4(1), 84-95.

Parry, E., \& Battista, V. (2019). The impact of emerging technologies on work: A review of the evidence and implications for the human resource function. Emerald Open Research, 1(5), 1-6. https://doi.org/10.12688/emeraldopenres.12907.1
Pedron, Z. (2018). The skills revolution of the 21st century: It's time to re-calibrate. Journal of European University Business School, 1(1), 1-116.

Prikshat, V., Biswas, K., Nankervis, A., \& Hoque, M.R. (2018). Bangladesh HR professionals' competencies: Impact on firm performance and moderating effects of organisation life cycle. Evidence-Based HRM: A Global Forum for Empirical Scholarship, 6(2), 203-220. https://doi.org/10.1108/EBHRM-12-2017-0064

Prisecaru, P. (2016). Challenges of the fourth industrial revolution. Knowledge Horizons. Economics, 8(1), 57-62.

Rana, G., \& Sharma, R. (2019). Emerging human resource management practices in industry 4.0. Strategic HR Review, 18(4), 176-181. https://doi.org/10.1108/ SHR-01-2019-0003

Rizvi, Y. (2011). Human capital development role of human resource (HR) during mergers and acquisitions. African Journal of Business Management, 5(2), 261-268.

Saunders, M., Lewis, P., \& Thornhill, A. (2015). Research methods for business students. New York, NY: Pearson.

Schäfer, M. (2018). The fourth industrial revolution: How the EU can lead it. European View, 17(1), 5-12. https://doi.org/10.1177/1781685818762890

Sharma, D. (2012). Roles for HR professionals. Integral Review: A Journal of Management, 5(2), 1-11. https://doi.org/10.1108/shr.2012.37211eaa.001

Shava, E., \& Hofisi, C. (2017). Challenges and opportunities for public administration in the fourth industrial revolution. African Journal of Public Affairs, 9(9), 203-215.

Sheehan, C., De Cieri, H., Greenwood, M., \& Van Buren III, H.J. (2014). HR professional role tensions: Perceptions and responses of the top management team. Human Resource Management, 53(1), 115-130. https://doi.org/10.1002/hrm.21574

Shenton, A.K. (2004). Strategies for ensuring trustworthiness in qualitative research projects. Education for Information, 22(2), 63-75. https://doi.org/10.3233/EFI2004-22201

Sivathanu, B., \& Pillai, R. (2018). Smart HR 4.0 - How industry 4.0 is disrupting HR. Human Resource Management International Digest, 26(4), 7-11. https://doi.org/ 10.1108/HRMID-04-2018-0059

Ślusarczyk, B. (2018). Industry 4.0: Are we ready? Polish Journal of Management Studies, 17(1), 232-248. https://doi.org/10.17512/pjms.2018.17.1.19

Ulrich, D., \& Brockbank, W. (2005). The HR value proposition. Boston: Harvard Business Press.

Ulrich, D., Younger, J., Brockbank, W., \& Ulrich, M. (2011). Competencies for HR professionals working outside-in. Retrieved from https://rblnet.s3.amazonaws. com/hrcs/2012/Competencies $\% 20$ for $\% 20$ HR $\% 20$ Professionals $\% 2$ Working $\% 20$ Com/hrcs/2012/Co

Ulrich, D., Younger, J., Brockbank, W., \& Ulrich, M. (2012). HR talent and the new HR competencies. Strategic HR Review, 11(4), 217-222. https://doi.org/10.1108/ competencies. Strategic
14754391211234940

Ulrich, D., Younger, J., Brockbank, W., \& Ulrich, M. (2013). The state of the HR profession. Human Resource Management, 52(3), 457-471. https://doi.org/ profession. Human

U, M., David, J.M. \& Kim, S.H. (2018). The fourth industrial revolution: Opportunities and challenges. International Journal of Financial Research, 9(2), 90-95. https:// doi.org/10.5430/ijfr.v9n2p90 